\title{
MAPEAMENTO DA VEGETAÇÃO NATIVA ORIGINAL EM ÁREAS ANTROPIZADAS NO ESTADO DE GOIÁS E DISTRITO FEDERAL UTILIZANDO GEOESTATÍSTICA
}

\author{
NATIVE VEGETATION MAPPING IN GOIÁS STATE AND IN THE FEDERAL \\ DISTRICT ANTHROPIZED AREAS USING GEOSTATISTICS
}

\author{
MAPEAMIENTO DE LA VEGETACIÓN ORIGINAL NATIVA EN ÁREAS \\ ANTROPIZADAS EN GOIÁS Y EN EL DISTRITO FEDERAL UTILIZANDO \\ GEOESTATÍSTICA
}

Cassio Henrique Giusti Cezare - Universidade Federal de Goiás - Goiânia- Goiás - Brasil

cassio_cezare@hotmail.com

Nilson Clementino Ferreira - Universidade Federal de Goiás - Goiânia - Goiás - Brasil

nclferreira@gmail.com

\section{Resumo}

A grande diversidade de espécies de animais e plantas está associada à diversidade de ambientes. Enquanto a estratificação vertical da Amazônia ou da Mata Atlântica proporciona oportunidades diversas para 0 estabelecimento das espécies, no Cerrado a heterogeneidade espacial parece ser um fator determinante para a ocorrência de um variado número de espécies. Os recursos computacionais disponíveis atualmente propiciaram ganhos significativos para as pesquisas geográficas. 0 presente trabalho teve como objetivo avaliar o potencial da geoestatística para elaborar um mapa da vegetação nativa original de Goiás e do Distrito Federal. Para entender a variação espacial, a variável vegetação foi analisada juntamente com outras três (solos, altitude e precipitação anual). Os valores do Erro Médio Padrão obtidos na Predição de Erros da Validação Cruzada e na Validação foram baixos. 0 modelo esférico e 0 interpolador cokrigagem apresentaram bons resultados na predição. Acredita-se que o resultado possa ser melhor, se for amenizado o fato de os maiores erros de predição estarem situados nas bordas da área de estudo e/ou próximos às áreas com menor densidade de pontos relativos à cobertura vegetal nativa (ex. Sul e Sudoeste goiano) ou com ausência de informação (ex. porção do bioma Mata Atlântica em Goiás).

Palavras-chave: mapeamento da cobertura vegetal nativa, geoestatística, cokrigagem, geotecnologias.

\section{Abstract}

The great diversity of animal species and plants is associated with the environment diversity. While the Amazon or Atlantic Forest vertical stratification provides many opportunities for species establishment, in Cerrado the spatial heterogeneity seems to be a determining factor for the occurrence of a varied number of species. The currently computational resources available promote significant gains for geographical research. This study aimed to evaluate geostatistics potential to elaborate an original native vegetation map of Goias State and of the Federal District. To understand the spatial variation, the vegetation variable was analyzed along with three others (soil, altitude, and annual precipitation). The Medium Error Standard values obtained in the Cross Validation Prediction Error and in the Validation were low. The spherical model and the cokriging interpolator demonstrated good results in the prediction process. The biggest prediction errors are situated at the edges of the study area and/or close to areas with lower point density related to the native vegetation (e.g. South and Southeast Goias) or with lack of information (e.g. Atlantic Forest biome portion in Goias).

Key words: native vegetation mapping, geostatistics, cokriging, geotechnology. 


\section{Resumen}

La gran diversidad de especies de animales y plantas está asociada a la diversidad de ambientes. Mientras la estratificación vertical del Amazonas o de la Selva Mata Atlántica (bosque) proporciona oportunidades diversas para el establecimiento de las especies, en el Cerrado la heterogeneidad espacial seria un factor determinante para que ocurra un variado número de especies. Los recursos computacionales disponibles actualmente proporcionan resultados significativos para las investigaciones geográficas. El presente trabajo tuvo por objetivo avaluar el potencial de la geoestadística para producir un mapa de la vegetación nativa original de Goiás y del Distrito Federal. Para entender la variación espacial, la variable vegetación fue analizada junto con otras tres (suelos, altitud y precipitación anual). Los valores de Error Medio Padrón obtenidos en la Predicción de Errores de Validación Cruzada y en Validación fueron bajos. El modelo esférico y el interpolador cokriging presentaron buenos resultados en la previsión. Se cree que el resultado pueda ser mejor, si es amenizado el hecho de los mayores errores de predicción estén situados en los bordes del área de estudio y/próximo de las zonas con menor densidad de puntos relativos a la cobertura vegetal nativa (ej. Sur y Sur-oeste goiano) o con ausencia de información (ej. Porción de bioma Atlántica en Goiás). Palabras claves: mapeamiento de la cobertura vegetal nativa, geoestatística, cokriging, geotecnologias.

\section{Introdução}

\section{Domínio Morfoclimático e Bioma: diferenças conceituais}

A grande diversidade de espécies de animais e plantas do Cerrado está associada à diversidade de ambientes. Enquanto a estratificação vertical da Amazônia ou da Mata Atlântica proporciona oportunidades diversas para o estabelecimento das espécies, no Cerrado a heterogeneidade espacial (a variação dos ecossistemas ao longo do espaço) seria um fator determinante para a ocorrência de um variado número de espécies. Os ambientes do Cerrado variam significativamente no sentido horizontal, sendo que áreas campestres, capões de mata, florestas e áreas brejosas podem existir em uma mesma região (Machado et al., 2004, p. 3).

De acordo com o documento Conservation International (2010), o Cerrado e a Mata Atlântica estão entre as cinco primeiras de um ranking composto por 34 regióes do planeta denominadas de hotspots. Esse número hoje é significativamente maior quando comparado ao apresentado por Myers et al. (2000, p. 853), que era de 25 hotspots, do qual os referidos biomas já faziam parte. O termo hotspots se refere às regiões biologicamente mais ricas e ameaçadas do planeta e com grande relevância para a conservação da natureza.

O termo "bioma" empregado no Mapa de Biomas do Brasil é definido como "[...] um conjunto de vida (vegetal e animal) constituído pelo agrupamento de tipos de vegetação contíguos e identificáveis em escala regional, com condições geoclimáticas similares e história compartilhada 
de mudanças, o que resulta em uma diversidade biológica própria” (IBGE, 2004a, c).

Esta definição, bem como seus limites geográficos são reconhecidos e utilizados por órgãos oficiais brasileiros (ex. MMA, Ibama, ICMBIO, Conama etc.) e instituições de pesquisa (CI Brasil, TNC, WWF, SOS Mata Atlântica, Embrapa Cerrados, UFG, UnB, UFMG, UFU, USP, Unesp, Unicamp etc.), por exemplo, para monitorar as taxas anuais de desmatamento ou se obter a área desmatada nesse ou naquele bioma, num dado estado ou município, considerando via de regra um intervalo de tempo.

Para Coutinho (2006, p. 8), “o domínio do cerrado compreende, portanto, distintos biomas, não são apenas fitofisionomias de um mesmo bioma. As diferenças entre estes ecossistemas vão muito além, conferem-lhes o caráter de biomas próprios. O bioma é um tipo de ambiente bem mais uniforme em suas características gerais, em seus processos ecológicos, enquanto que o domínio é muito mais heterogêneo. Bioma e domínio não são, pois, sinônimos. Usá-los como sinônimos é particularmente perigoso para a preservação e conservação das matas de galeria, matas tropicais estacionais sempre verdes, semicaducifólias ou caducifólias e outros biomas, pois significa considerá-las como partes integrantes do bioma do cerrado, que, pela Constituição de 1988, não é considerado "patrimônio nacional."

Geograficamente, Ab’Sáber (2003, p. 11-12) apresenta a definição para domínio morfoclimático e fitogeográfico como sendo,

um conjunto espacial de certa ordem de grandeza territorial - de centenas de milhares a milhões de quilômetros quadrados de área onde haja um esquema coerente de feições de relevo, tipos de solos, formas de vegetação e condições climático-hidrológicas. Tais domínios espaciais, de feições paisagísticas e ecológicas integradas, ocorrem em uma espécie de área principal, de certa dimensão e arranjo, em que as condições fisiográficas e biogeográficas formam um complexo relativamente homogêneo e extensivo. A essa área mais típica e contínua - via de regra de arranjo poligonal, aplicamos o nome de área core, logo traduzida por área nuclear - termos indiferentemente empregados, segundo o gosto e as preferências de cada pesquisador.

Em território brasileiro, Ab’Sáber (2003, p. 12) destaca que são reconhecidos seis grandes domínios paisagísticos e macroecológicos, sendo que os cinco primeiros possuem arranjo, em geral, poligonal, con- 
siderando-se suas áreas core: i) Domínio das terras baixas florestadas da Amazônia; ii) Domínio dos chapadões centrais recobertos por cerrados, cerradões e campestres; iii) Domínio das depressões interplanálticas semiáridas do Nordeste; iv) Domínio dos "mares de morros" florestados; v) Domínio dos planaltos de araucárias; e vi) Domínio das pradarias mistas do Rio Grande do Sul. Na representação cartográfica dos Domínios morfoclimáticos brasileiros o autor, entre um e outro domínio, "preenche" com o que chama de Faixa de Transição.

O termo "domínio", absorvido nos trabalhos de SBPC (2010) e de Machado et al. (2004, p. 2), é um caminho para no Cerrado se explicar, por exemplo, a relação com o meio físico de algumas fitofisionomias integrantes da formação florestal (ex. mata ciliar, mata de galeria e mata seca), bem como as enquadradas nas formações savânica e campestre. Assim como aquela, essas também são propostas por Ribeiro e Walter (1998).

Para alguns autores (Barbosa, 1996; Felfili e Silva Júnior, 2001; Felfili, 2003; Oliveira-Filho e Ratter, 2002), os corredores hidrográficos com suas matas ciliares, matas de galeria, buritizais, veredas e brejos, tendo ou não como vizinhança as matas secas ou florestas estacionais, são responsáveis pela interligação da flora e da fauna dos Cerrados com as de outros domínios morfoclimáticos, biomas, ecorregiões, ecossistemas, sistemas ecológicos ou complexos vegetacionais.

No presente trabalho, o termo "bioma" foi empregado como referência aos mapas, estudos e divisões oficiais, observando-se, porém, que domínio morfoclimático foi o conceito utilizado nas correlações e análises, em razão de sua abrangência e de se tratar de um trabalho essencialmente geográfico.

Conhecimento: dos viajantes e naturalistas ao uso das geotecnologias

Vários foram os naturalistas, militares e viajantes (Saint-Hilare, 1975; Spix e Martius, 1938; Mattos, 1979; Leal, 1980, entre outros) que no século XIX, no ainda Brasil Colônia, passaram pela antiga Província de Goiás. A região também foi objeto, em meados do século XX, de estudos de renomados geógrafos, como Faissol (1952) e Waibel (1958), que abordaram a porção Centro-sul de Goiás, e Ab’Sáber e Costa Júnior (1951), com as célebres descrições do meio físico, dos costumes, das habitações e do uso da terra no Sudoeste goiano. 
É grande o legado de informações colhidas e registradas por essas pessoas, seja pelas espécies vegetais e animais descritas e catalogadas, pelas estatísticas sociais e administrativas geradas, pelas observações acerca da geologia, do clima, do uso da terra, dos costumes, do modo de vida, entre outras.

Não menos importante é a obra Chorographia Histórica da Província de Goiáz (Mattos, 1979), escrita na década de 1920 por Raymundo José da Cunha Mattos, Governador das Armas da Província de Goiás à época.

Apesar de todo o esforço mais recente para realizar trabalhos de campo e para transcrever e/ou descrever observações colhidas no passado e na atualidade, Goiás não dispõe de um mapa da cobertura vegetal nativa original.

Nem todos os relatos e/ou descrições acerca da vegetação nativa ou do uso da terra contidos nesses documentos apresentam um par de coordenadas geográficas, quando muito uma latitude, o que tem dificultado inferências ou mesmo a reconstrução da abrangência original da vegetação.

Waibel (1958, p. 187-188) já atentava para os benefícios que o advento das fotografias aéreas usadas antes, durante e depois da II Guerra Mundial poderiam trazer à geografia, à botânica, à fitogeografia e à elaboração de um mapa de vegetação. Para o autor, a combinação delas com mapas cadastrais, estudos críticos de descrições de viagens (muitas na forma mesmo de caminhadas), ou ainda com nomes de lugares (toponímia) que apresentassem relação com "mata”, "mato”, “campo”, "campestre”, ou nomes de árvores/plantas, constituiria fonte valiosa de informação.

Com a vocação de pesquisador, pode-se dizer que Waibel foi um, se não o primeiro, geógrafo no Brasil a se atentar, na época, para a necessidade de representar com maior exatidão os tipos vegetacionais e sua distribuição nas diversas regiões do país. Tanto que na obra Capítulos de Geografia Tropical e do Brasil (Waibel, 1958, p. 183-190), no capítulo "A elaboração de um novo mapa de vegetação do Brasil", o autor traz dois termos muito atuais e necessários ao tratar do tema, que são: "reconstrução" e "reconstituição".

Machado et al. (2004) e Sano et al. (2008), em pesquisas recentes, mapearam o bioma Cerrado. Os valores obtidos por eles de cobertura vegetal nativa (45,1 e 60,5\% respectivamente) para o ano base 2002 trazem preocupação no ano de 2012, em que o desenvolvimento sustentável foi discutido num evento promovido pela Organização das Nações Unidas 
(ONU) (Rio+20). Não por acaso e por o Brasil ser signatário da Convenção sobre Diversidade Biológica (CDB), após esses estudos, o bioma passou a integrar o Projeto de Monitoramento do Desmatamento nos Biomas Brasileiros por Satélite (PMDBBS), ligado ao Ministério do Meio Ambiente (MMA).

A perda de cobertura vegetal nativa no Cerrado entre 2002 e 2008 foi de $14.200 \mathrm{~km}^{2} / \mathrm{ano}$, totalizando $85.074,87 \mathrm{~km}^{2}$ para o período todo (Bra-

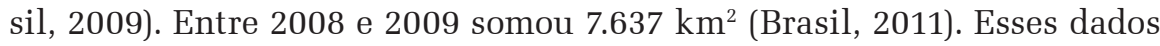
alertam para a efetiva necessidade de adoção de políticas públicas já previstas para esse bioma no que tange à prevenção e o controle do desmatamento e o uso sustentável dos recursos naturais.

Essas políticas fazem parte do Programa Nacional de Conservação e Uso Sustentável do Bioma Cerrado (Brasil, 2006b) e do Plano de Ação para Prevenção e Controle do Desmatamento e das Queimadas no Cerrado (Brasil, 2010).

Contribuições para elaboração do mapa da cobertura nativa original

Baseado em ESRI (2008), a cokrigagem é um interpolador geoestatístico moderadamente rápido, que pode fornecer resultados exatos ou regulares, dependendo do modelo de predição empregado. Nesse interpolador, podem ser analisadas múltiplas séries de dados, e sua flexibilidade permite que gráficos de correlação cruzada e de autocorrelação sejam analisados.

Ainda de acordo com ESRI (2008), esse interpolador emprega modelos estatísticos que permitem uma variedade de mapas de saída que incluem predições, erros padrões de predição, probabilidades, entre outros. A sua versatilidade exige, contudo, atenção na tomada de decisão, pois supõe que os dados são provenientes de um processo estocástico estacionário ou que os dados possuem distribuição normal.

A decisão pela interpolação com a cokrigagem teve como objetivo, a partir do conceito de domínio morfoclimático, entender os padrões atuais da organização espacial dos remanescentes de vegetação nativa e os processos que os favoreceram. Para tanto, optou-se pela entrada de múltiplas variáveis no interpolador, entre as quais a própria vegetação nativa, a fisiografia (altitude), os solos e o clima (pluviosidade anual).

O presente trabalho teve como objetivo final, a "reconstrução" da distribuição da cobertura vegetal nativa no estado de Goiás e Distrito Fe- 
deral empregando a cokrigagem, que em suas rotinas de processamento permite a modelagem preditiva de uma variável a partir de informações existentes na "vizinhança" de um dado ponto ou local que não a apresente, por exemplo, valores de fertilidade de solo colhidos num campo que está sendo preparado para ser agricultável.

Imagina-se que a pesquisa possa apoiar a resolução/recuperação de passivos ambientais, a exemplo da ausência de vegetação nativa em áreas de preservação permanente (APP) ou de reserva legal (RL) situadas em municípios onde a cobertura vegetal é praticamente inexistente, carecendo, assim, de um referencial, que pode ser complementado com informações de estudos fitossociológicos já existentes, ambos cruciais na escolha de espécies arbóreas e do modelo de recomposição ambiental a ser empregado. Espera-se também que o resultado da pesquisa, seja utilizado no ordenamento territorial e na criação de unidades de conservação (UCs) em regiões de Goiás com baixa incidência de UCs, haja vista que o Distrito Federal dispõe de significativo número de áreas protegidas.

Material e métodos

\section{Região de estudo}

A região de estudo (Figura 1) compreende os limites do estado de Goiás e do Distrito Federal e se localiza entre os paralelos $12^{\circ} 20^{\prime} 00^{\prime} \mathrm{S}$ e $19^{\circ} 30^{\prime} 00^{\prime} \mathrm{S}$ e os meridianos de $45^{\circ} 50^{\prime} 00^{\prime \prime} \mathrm{W}$ e $53^{\circ} 16^{\prime} 00^{\prime \prime} \mathrm{W}$.

O domínio dos chapadões centrais recobertos por cerrados, cerradões e campestres ocupa todo o Distrito Federal e praticamente toda a extensão do estado de Goiás, salvo numa estreita faixa na divisa com Minas Gerais, na margem direita do rio Paranaíba, onde, de acordo com Ab’Sáber (2003, p. 12), ocorre a faixa de transição com domínio dos "mares de morros" florestados.

A porção do Cerrado na área de estudo representa aproximadamente 17\% da área total do bioma no país. Já a área do bioma Mata Atlântica em Goiás representa cerca de 1\% do total do bioma no Brasil; este, porém, não abrange os limites do Distrito Federal. 


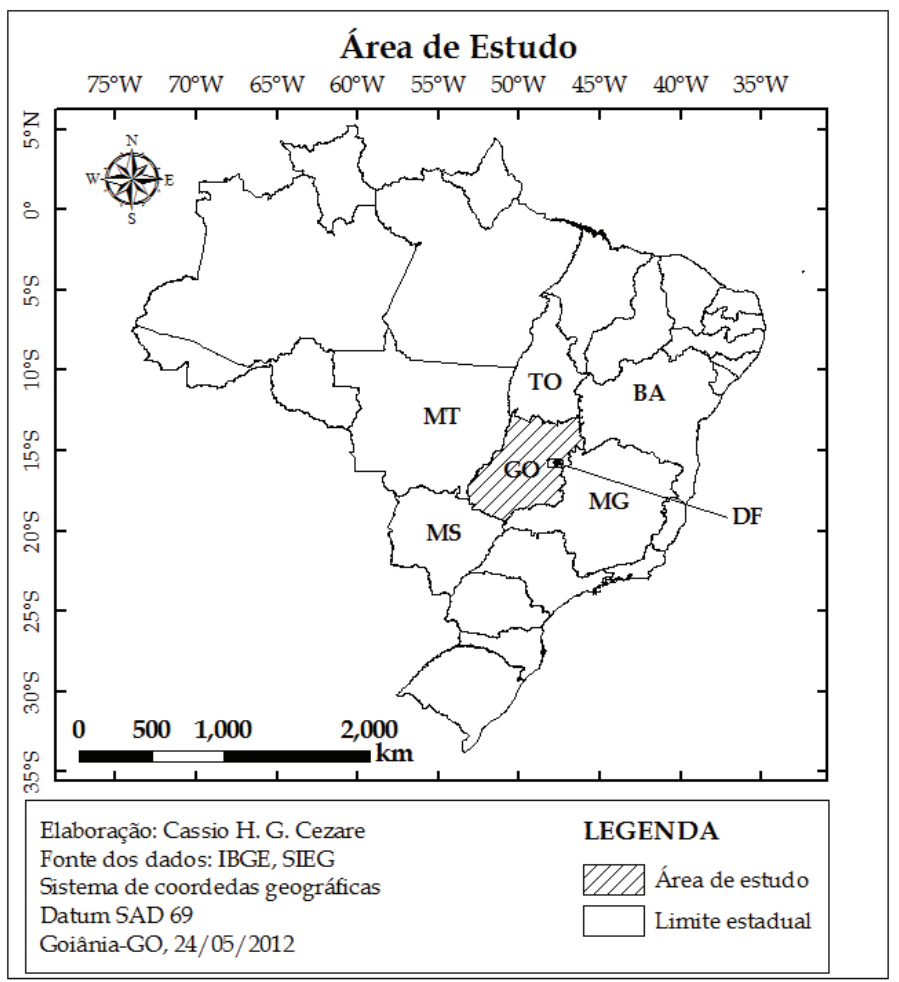

Figura 1 - Localização da área de estudo.

\section{Base de dados e aplicativos}

Os mapas de Goiás e do DF relativos à hipsometria (relevo) e solos, empregados no estudo, foram obtidos junto ao Sistema Estadual de Estatística e Informações Geográficas de Goiás (SIEG, 2011), e estão disponíveis nas escalas 1.250.000 e 1:1.000.000, respectivamente.

As altitudes na região de estudo situam-se entre 100 e 1.700 metros, sendo os valores mais frequentes os compreendidos entre 300 e 900 metros. Considerando a forma como foi elaborado o mapa de solos na base do SIEG, as classes de solos na região são em número de 308, contabilizando-se as 29 associações de mais de uma classe de solos.

O tema solo originalmente incluía a classe água, a qual se refere aos grandes lagos artificiais existentes na área de estudo, a exemplo do lago 
Paranoá no DF. Contudo, foi excluída do processamento e análise, por não se tratar de um tipo de solo e não representar poligonalmente os rios, lagos e lagoas naturais e sim um tipo de antropismo (uso da terra), neste caso o represamento para fins de abastecimento humano ou de geração de energia elétrica.

O relevo na base do SIEG se apresenta com oito classes de altitude, cada qual com amplitude de 200 metros (Tabela 1). A amplitude de cada classe não foi alterada, pois assume-se que ela é significativa para expressar a relação espacial com as fitofisionomias ou classes de vegetação propostas pelo Probio/MMA (Brasil, 2006a).

Tabela 1 - Classes de altitude presentes na área de estudo.

\begin{tabular}{|c|c|}
\hline Classe & Intervalo (metros) \\
\hline 1 & $100-300$ \\
\hline 2 & $300-500$ \\
\hline 3 & $500-700$ \\
\hline 4 & $700-900$ \\
\hline 5 & $900-1.100$ \\
\hline 6 & $1.100-1.300$ \\
\hline 7 & $1.300-1.500$ \\
\hline 8 & $1.500-1.700$ \\
\hline
\end{tabular}

Fonte: Adaptado de SIEG (2011)

O dado sobre clima, neste caso pluviosidade anual, também foi obtido no SIEG. Contudo, esse tema não apresenta escala, por se tratar de informações pontuais relativas às 114 estações climatológicas (localidades) administradas pelo Sistema de Meteorologia e Hidrologia do Estado de Goiás (Simehgo) da Secretaria de Estado de Ciência e Tecnologia de Goiás ou pelo Instituto Nacional de Meteorologia (Inmet).

O mapa de cobertura vegetal nativa e uso da terra foi produzido a partir da base de dados geográficos do Probio/MMA - Ano Base 2002 (Brasil, 2006a), disponível na escala 1:250.000. Para a área de abrangência do estudo constam treze atributos de classes de vegetação natural (Figura 2), as quais estão descritas juntamente com as quatro classes de uso antrópico (Tabela 2). 
Tabela 2 - Atributos de classes de vegetação nativa na área de estudo.

\begin{tabular}{|c|c|c|c|c|c|c|}
\hline & & & Classe & Descrição & $\begin{array}{c}\text { Área } \\
\text { (hectares) }\end{array}$ & $\begin{array}{c}\text { Contribuição } \\
(\%)\end{array}$ \\
\hline \multirow{2}{*}{\multicolumn{2}{|c|}{ 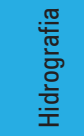 }} & 1 & Agua & Água & $383.287,27$ & 0,78 \\
\hline & & \multicolumn{3}{|r|}{ SUBTOTAL } & $383.287,27$ & 0,78 \\
\hline \multirow{5}{*}{\multicolumn{2}{|c|}{ 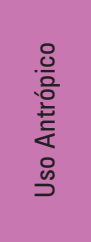 }} & 1 & Ac & Cultura Agrícola & $6.074 .805,63$ & 12,30 \\
\hline & & 2 & Ap & Pastagem Cultivada & $18.235 .482,59$ & 36,92 \\
\hline & & 3 & lu & Influência Urbana & $285.438,98$ & 0,58 \\
\hline & & 4 & R & Reflorestamento & $59.664,21$ & 0,12 \\
\hline & & \multicolumn{3}{|r|}{ SUBTOTAL } & 24.655.391,41 & 49,91 \\
\hline \multirow{17}{*}{ 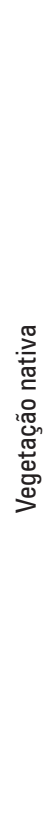 } & \multirow{7}{*}{$\begin{array}{l}\frac{\pi}{\Delta} \\
\text { d } \\
\text { 흔 }\end{array}$} & 1 & $\mathrm{Cm}$ & Floresta Estacional Decidual Montana & $4.027,63$ & 0,01 \\
\hline & & 2 & Cs & Floresta Estacional Decidual Submontana & $614.510,08$ & 1,24 \\
\hline & & 3 & $\mathrm{Fa}$ & Floresta Estacional Semidecidual Aluvial & $1.263 .925,38$ & 2,56 \\
\hline & & 4 & $\mathrm{Fm}$ & Floresta Estacional Semidecidual Montana & $13.130,13$ & 0,03 \\
\hline & & 5 & Fs & Floresta Estacional Semidec. Submontana & $414.347,42$ & 0,84 \\
\hline & & 6 & $\mathrm{~Pa}$ & Formação Pioneira & 909,13 & 0,002 \\
\hline & & \multicolumn{3}{|r|}{ SUBTOTAL } & $2.310 .849,77$ & 4,68 \\
\hline & \multirow{8}{*}{ 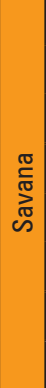 } & 1 & Saf & Savana Arborizada com Floresta de Galeria & $4.854 .240,56$ & 9,83 \\
\hline & & 2 & Sas & Savana Arborizada sem Floresta de Galeria & $6.387 .053,06$ & 12,93 \\
\hline & & 3 & Sd & Savana Florestada & $916.886,78$ & 1,86 \\
\hline & & 4 & Sgf & Savana Gram. Lenhosa com Floresta de Galeria & $754.924,50$ & 1,53 \\
\hline & & 5 & Sgs & Savana Gramíneo Lenh. sem Floresta de Galeria & $80.268,43$ & 0,16 \\
\hline & & 6 & Spf & Savana Parque com Floresta de Galeria & 7.007.176,58 & 14,19 \\
\hline & & 7 & Sps & Savana Parque sem Floresta de Galeria & $2.009 .533,00$ & 4,07 \\
\hline & & & & SUBTOTAL & $22.010 .082,90$ & 44,56 \\
\hline & \multirow{2}{*}{$\begin{array}{l}\stackrel{\sim}{\sim} \\
\dot{D} \\
\stackrel{\Delta}{\circ}\end{array}$} & 1 & Vs & Vegetação Secundária (Veg. 2ª) & $38.409,63$ & 0,08 \\
\hline & & \multicolumn{3}{|r|}{ SUBTOTAL } & $38.409,63$ & 0,08 \\
\hline \multicolumn{2}{|c|}{$\begin{array}{l}\text { TOTAL } \\
\text { GERAL }\end{array}$} & \multicolumn{3}{|c|}{19} & 49.398.020,97 & 100 \\
\hline
\end{tabular}

Fonte: Adaptado de Probio/MMA - ano base 2002 (Brasil, 2006a).

A lacuna de informações no mapa referente ao Sul goiano se deve ao fato de, à época da realização dos trabalhos do Probio, as equipes res- 
ponsáveis pelos biomas Mata Atlântica e Cerrado não terem efetuado o mapeamento nessa porção da área de estudo.

Como ferramenta de representação cartográfica dos dados, utilizou-se um software de SIG (Sistema de Informação Geográfica), neste caso, o ArcGIS (ESRI, 2008).

Antes e após a entrada dos dados das 4 variáveis empregadas no interpolador do software, algumas tarefas foram executadas, utilizando-se as ferramentas disponíveis no ArcToolbox do citado programa, a saber:

Ferramentas de Análise (Analysis Tools)

1.1 - Extrair (Extract)

1.1.1 - Cortar (Clip)

1.1.2 - Escolher (Select)

1.2 - Sopreposição (Overlay)

1.2.1 - Apagar (Erase);

Ferramentas para Conversão (Conversion Tools)

2.1 - Para Raster ou Matricial (To Raster)

2.1.1 - Polígono para Raster ou Matricial (Polyline to Raster)

2.2 - De Raster ou Matricial (From Raster)

2.2.1 - Raster ou Matricial para Ponto (Raster to Point)

2.2.2 - Raster ou Matricial para Polígono (Raster to Polygon)

Ferramentas de Análises Espaciais (Spatial Analyst Tools)

3.1 - Matemática (Math)

3.1.1 - Converter para números inteiros (Int)

Análises Geoestatísticas (Geostatistical Analyst)

4.1 - Criando Subconjuntos (Create Subsets)

4.1.1 - Subconjuntos (Percent/Samples - Training e Testing)

4.2 - Assistente de Geoestatística (Geostatistical Wizard)

4.2 - Métodos (Methods)

4.2.1 - Cokrigagem (Cokriging)

4.2.1.1 - Krigagem Simples (Simple Kriging)

Junções e Relações (Join and Relates)

5.1 - Junções (Join)

Ferramentas de Estatísticas Espaciais (Spatial Statistics Tools)

6.1 - Utilidades (Utilities)

6.1.1 - Cálculo de Áreas (Calculate Areas) 
Projeções e Transformações (Projections and Transformations) 7.1 - Feição/Característica (Feature)

7.1.1 - Sistemas de Coordenadas Projetadas (Projected Coordinate Systens)

\subsubsection{1 - Continental (Continental)}

7.1.1.1.1 - América do Sul (South America)

7.1.1.1.1.1 - Projeção Cônica de Albers com Igualdade de Área para América do Sul (South America Equal Area Conic.prj)

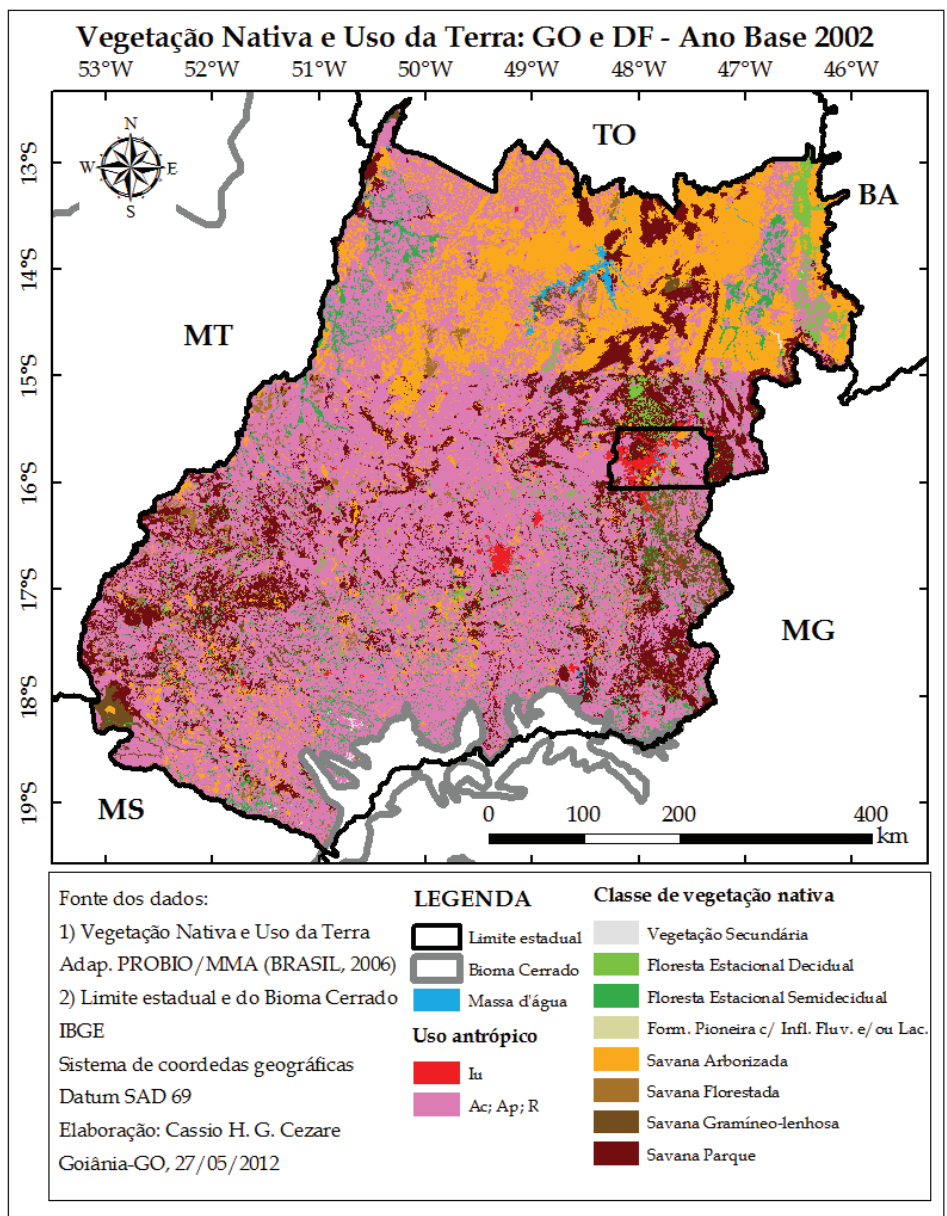

Figura 2 - Uso do solo e cobertura vegetal na área de estudo. 
Para o cálculo das áreas, os polígonos resultantes da interpolação foram reprojetados empregando-se a projeção cônica de Albers com igualdade de área para América do Sul, a fim de afetar o menos possível a forma e as dimensões dos mesmos.

Interpolação dos dados de cobertura vegetal nativa

As classes de vegetação nativa geradas pelo software seguiram a classificação proposta pelo Projeto de Conservação e Utilização Sustentável da Diversidade Biológica Brasileira - Probio (Brasil, 2009), a qual é adaptada dos mapas do projeto Radambrasil, a exemplo dos contidos em Brasil (1981, 1982, 1983).

Na modelagem dos dados de vegetação nativa utilizou-se o interpolador geoestatístico Cokrigagem Simples (Cokriging Simple) disponível no software.

O modelo esférico (spherical) empregado no semivariograma foi utilizado sem alteração dos parâmetros padrões (default) definidos pelo software.

Os arquivos matriciais (raster) das variáveis (vegetação, solos e relevo) foram gerados a partir dos arquivos tipo vetorial (shapefile) utilizando-se um grid de 500 metros, os quais depois foram convertidos para pontos, uma pré-condição do interpolador.

Com o objetivo de efetuar a validação da interpolação pela cokrigagem, a amostra de 764.566 pontos resultantes da conversão do mapa vetorial de vegetação nativa de Goiás e Distrito Federal foi dividida em dois subconjuntos. Nesse procedimento, utilizou-se a ferramenta "Criando Subconjuntos" (Create Subsets) do software. Os subconjuntos ficaram assim: $50 \%$ ( $n=382.283$ pontos) para ser empregado no mapa de predição e $50 \%$ ( $\mathrm{n}=382.283$ pontos) para ser empregado na validação do resultado da predição.

Os pontos citados anteriormente contemplam apenas as treze classes de vegetação nativa mapeadas pelo PROBIO na área de estudo. Observe-se que, antes da conversão do vetorial poligonal em pontual, as quatro classes de uso antrópico e a massa d'água foram excluídas da análise, por não se tratarem de classes de cobertura vegetal nativa. O mesmo ocorreu com a classe vegetação secundária, que não detalha a fitofisionomia. 
Os dados relativos às estações pluviométricas foram inseridos no interpolador na forma original (pontos), após ter sido acrescentanda uma coluna (pluviosidade anual), resultante da somatória da pluviosidade mensal disponível na tabela de atributos do tema (shapefile).

Resultados e discussão

Os valores da Predição de Erros (Prediction Errors) obtidos pelo interpolador na Validação Cruzada (Cross Validation), empregando um dos subconjuntos de pontos do Probio (50\% - training), e na Validação (Validation), que empregou o restante dos pontos (50\% - testing), podem ser observados na Tabela 3.

Tabela 3 - Valores da predição de erros obtidos pelo interpolador.

\begin{tabular}{|l|c|c|}
\hline \multirow{2}{*}{ Parâmetro } & Validação Cruzada & Validação \\
\cline { 2 - 3 } & Valor & Valor \\
\hline Média & $-0,002146$ & 0,006802 \\
\hline Raiz Quadrada Média & 1,867 & 1,822 \\
\hline Erro Médio Padrão & 2,793 & 2,793 \\
\hline Média Padronizada & $-0,0008006$ & 0,002405 \\
\hline Raiz Quadrada Média Padronizada & 0,6684 & 0,6523 \\
\hline
\end{tabular}

O erro médio, assim como o erro médio padrão, podem ser considerados baixos, pois são menores e menos significativos frente aos obtidos por outros interpoladores (ex. Krigagem Simples e Ordinária), os quais não permitem a entrada de múltiplas variáveis.

Para melhor visualização do mapa da cobertura vegetal nativa original ou mapa de predição (Figura 03), alguns subtipos vegetacionais ou grupos de formação (ex. aluvial, submontana, montana, com ou sem floresta-de-galeria) gerados pelo interpolador foram agrupados por região fitoecológica (ex. Floresta Estacional Semidecidual) ou áreas de vegetação (ex. Formações Pioneiras), como sugere IBGE (1992, 2004b).

Além desse produto, o interpolador permite, ainda, a elaboração de um mapa com o erro padrão de predição (Figura 4), obtido em cada região modelada da área de estudo, o que pode ser útil no aperfeiçoamento do resultado da modelagem. 
Das treze classes de vegetação existentes na área de estudo, o interpolador retornou onze. Os tipos Cm (Floresta Estacional Decidual Montana) e Sps (Savana Parque sem floresta-de-galeria) não estão representados no mapa de predição, pois seus valores não foram contemplados na interpolação, que oscilou de 1,67 a 12,90. Isso pode estar relacionado ao fato de o modelo e parâmetros empregados não terem se ajustado ou identificado todos os padrões de distribuição espacial da vegetação nativa quando associados às variáveis escolhidas nesse estudo.

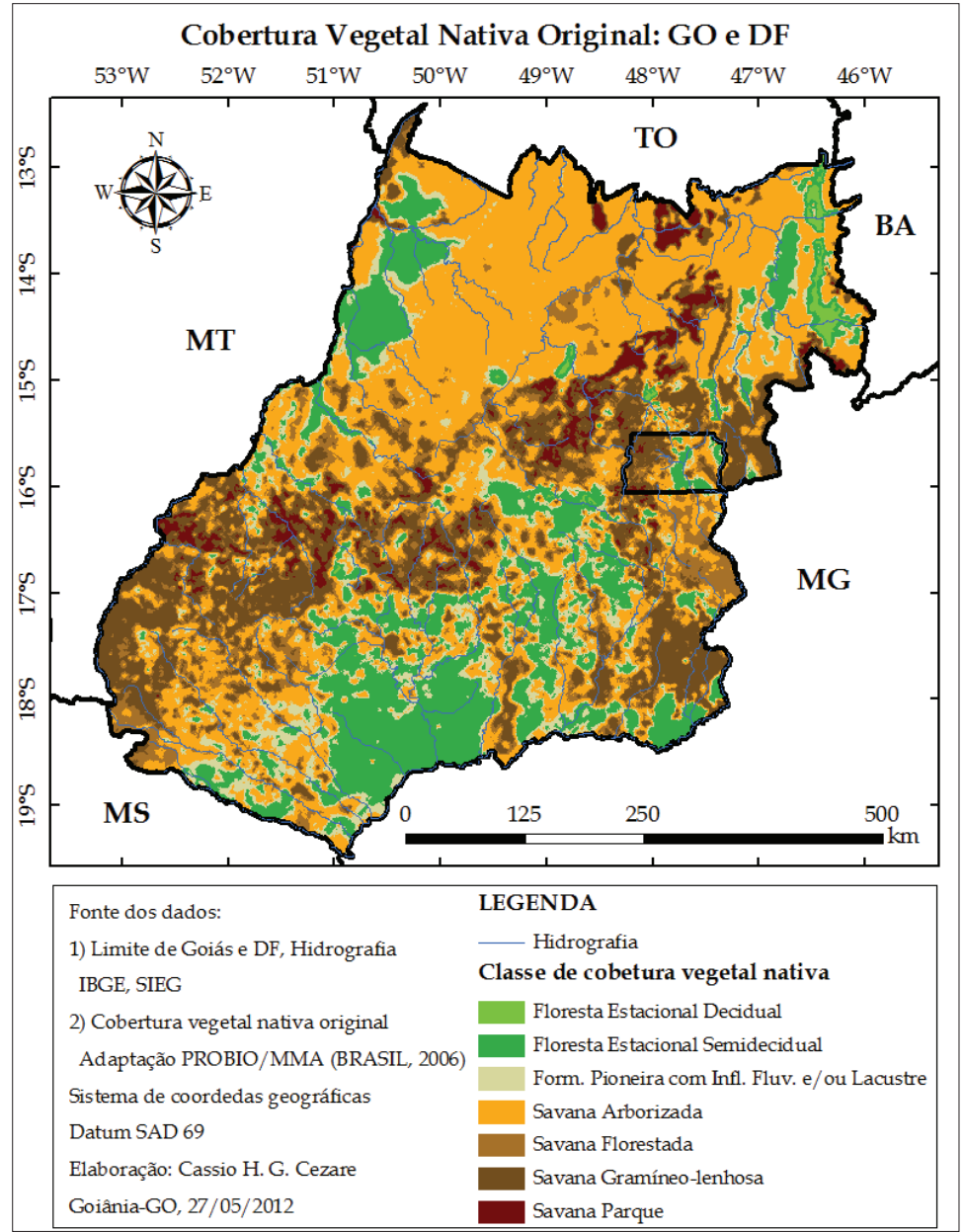

Figura 3 - Representação da cobertura vegetal nativa original obtida pelo interpolador. 
O tipo Cm talvez seja um caso particular, pois além de estar entre as classes com menor frequência de dados, ocorre sobre um subtipo de cambissolo com distribuição restrita na parte Leste da área de estudo, apesar de ocorrer sobre classe de relevo frequente (700-900 metros).

A classe Sps é um dos tipos de vegetação com maior ocorrência na área de estudo, consequentemente maior frequência de dados ou pontos da classe foram inseridos na modelagem. $\mathrm{O}$ fato de não ter figurado no mapa de predição pode estar relacionado, em parte, ao critério que adota a ferramenta "Arredondamento" (Int) do software.

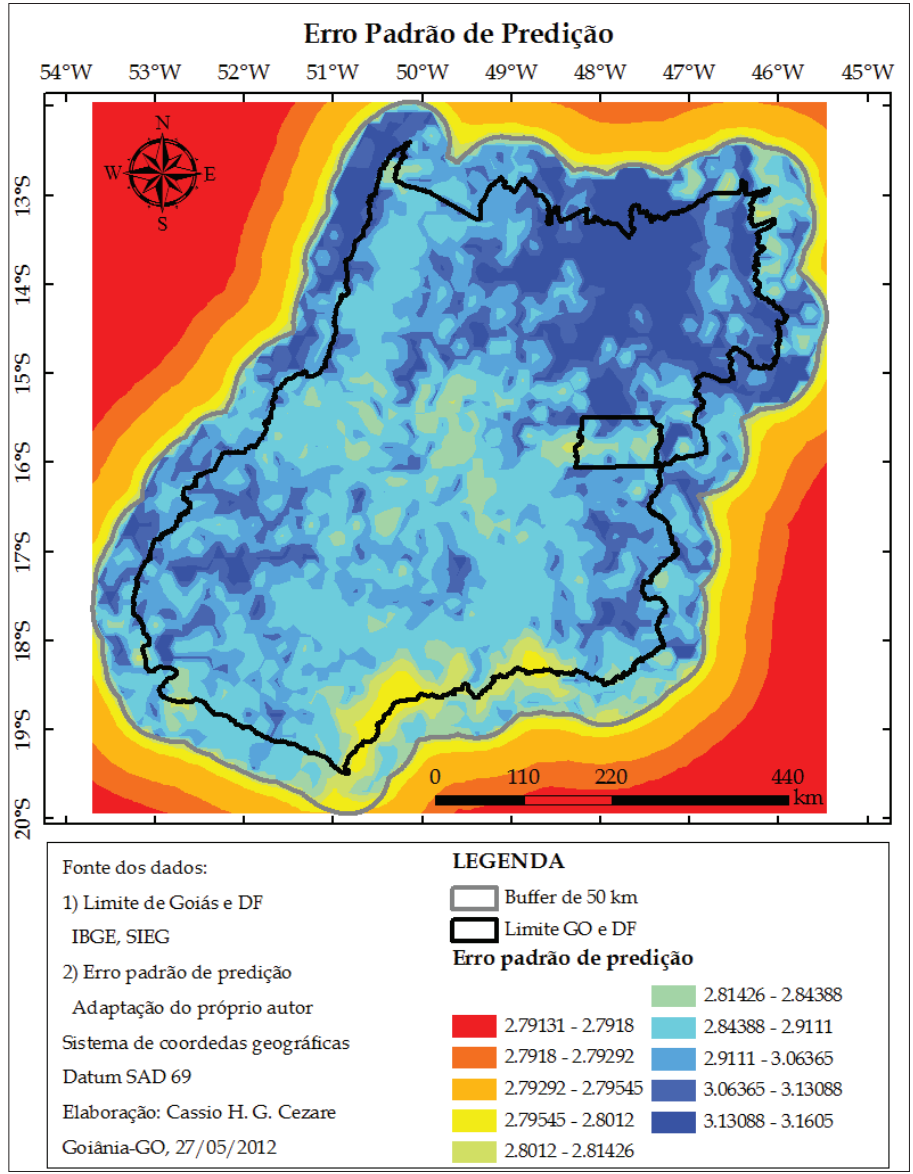

Figura 4 - Mapa do erro padrão de predição. 
O emprego da base de solos na escala 1:1.000.000, em comparação à de vegetação e de relevo, que são 1:250.000, certamente influenciou na situação descrita acima, a qual é agravada pela malha reduzida de pontos de pluviosidade ou estações metereológicas na área de estudo.

Na região Sudoeste de Goiás, em porções dos municípios de Caçu, Cachoeira Alta, Paranaiguara, São Simão, Quirinópolis e Gouvelândia, sobre solos do tipo latossolo-roxo e latossolo vermelho-escuro, onde ocorre predominantemente a pecuária (pastagem), o interpolador trouxe como resultado a ocorrência de Floresta Estacional Semidecidual, subtipos montana (Fm) e aluvial (Fa), cuja distribuição natural é compatível com essas classes de solo, ditas popularmente como "terras de cultura" ou de "mata".

Essa região compreende os interflúvios dos rios Claro, Alegre, Preto, São Francisco, dos Bois e Meia Ponte, ambos afluentes da margem direita do rio Paranaíba.

No Norte e Nordeste goiano, onde incidem os maiores remanescentes de vegetação nativa, ocorreu predição positiva pelo interpolador, em especial nas classes Savana Arborizada sem floresta-de-galeria (Sas) e Savana Arborizada com floresta-de-galeria (Saf). Isso se deve ao grid concentrado de pontos que essas tipologias permitiram inserir no interpolador, garantindo alta correlação entre o real/observado e a predição.

\section{Considerações finais}

Para o contínuo de remanescentes de vegetação nativa existentes na porção Centro-norte da área de estudo, o modelo e o interpolador empregados apresentaram bons resultados no mapa de predição.

A interpolação empregada também mostrou potencial no que se refere à predição de vegetação nativa em áreas atualmente ocupadas por algum uso antrópico, como é o caso das pastagens existentes no Sudoeste goiano.

Há necessidade de se ajustar melhor os dados de cobertura vegetal nativa com as variáveis empregadas, como, por exemplo, testar outros modelos e parâmetros do interpolador disponíveis no software, na tentativa de minimizar os erros de predição.

Faz-se necessário, também, testar outras variáveis climáticas, além da utilizada neste estudo, mesmo sabendo que a pluviosidade está, em parte, relacionada com o relevo (orografia) em escala regional. 
A distância da vegetação em relação à calha dos principais rios da área de estudo talvez seja uma variável forte a ser testada, visto que pelo menos cinco tipologias do Probio/MMA tem relação com floresta-de-galeria ou sofrem algum tipo de influência fluvial e/ou lacustre.

Acredita-se que o resultado da interpolação possa ser melhor se for amenizado o fato de os maiores erros de predição estarem situados nas bordas da área de estudo e/ou próximos às áreas com menor densidade de pontos relativos à cobertura vegetal nativa, a exemplo do Sul e Sudoeste goiano, ou com ausência de informação, como é o caso da porção do bioma Mata Atlântica em Goiás.

Deve-se considerar o fato de a variável vegetação nativa, bem como as demais analisadas serem qualitativas e não quantitativas, como comumente se emprega na geoestatística.

Uma alternativa condicionada à disponibilidade de base cartográfica, mesmo que em escala de reconhecimento ou de síntese (ex: 1:250.000 ou menores), seria estabelecer um buffer de pontos maior do que o empregado em algumas variáveis (50 km para vegetação e $10 \mathrm{~km}$ para relevo).

Informações, mesmo que pertencentes a outro bioma ou outro estado vizinho, mas que possuam ocorrência natural na área de estudo (ex. Floresta Estacional subtipos semidecidual e decidual), também poderiam ser empregadas.

Dados de inventários florestais, estudos florísticos e fitossociológicos realizados nas áreas com ausência ou insuficiência de pontos, seriam outras fontes de informações para ajudar a diminuir os erros na predição.

\section{Agradecimentos}

Agradecemos à Coordenação de Aperfeiçoamento de Pessoal de Nível Superior (CAPES) pelo apoio financeiro com a concessão de bolsa de pesquisa em nível de mestrado ao então mestrando Cassio H. G. Cezare entre março de 2010 e março de 2012. Ao Conselho Nacional de Desenvolvimento Científico e Tecnológico (CNPQ) pela concessão de bolsa de produtividade em pesquisa - nível 2 ao Prof. Dr. Nilson Clementino Ferreira.

\section{Referências}

AB'SÁBER, A. N. Os domínios de natureza no Brasil: potencialidades paisagísticas. São Paulo: Ateliê, 2003. 
AB'SÁBER, A. N.; COSTA JÚNIOR, M. Contribuição ao estudo do Sudoeste goiano. Boletim Geográfico, Rio de Janeiro, v. 9, n. 98, p. 123-138, maio 1951.

BARBOSA, A. S. Sistema biogeográfico do cerrado: alguns elementos para sua caracterização. Goiânia: Ed. UCG, 1996. 44 p., mapas, graficos.

BRASIL. Ministério de Minas e Energia. Secretaria Geral. Projeto RADAMBRASIL: Levantamento de Recursos Naturais: Geologia, Geomorfologia, Pedologia, Vegetação e Uso Potencial da Terra. Folha SD-22, Goiás, v. 25. Rio de Janeiro: MME/SG, 1981. 640p. il.

BRASIL. Ministério de Minas e Energia. Secretaria Geral. Projeto RADAMBRASIL: Levantamento de Recursos Naturais: Geologia, Geomorfologia, Pedologia, Vegetação e Uso Potencial da Terra. Folha SD-23, Brasília, v. 29. Rio de Janeiro: MME/SG, 1982. 660p. il.

BRASIL. Ministério de Minas e Energia. Secretaria Geral. Projeto RADAMBRASIL: Levantamento de Recursos Naturais: Geologia, Geomorfologia, Pedologia, Vegetação e Uso Potencial da Terra. Folha SE-22, Goiás, v. 31. Rio de Janeiro: MME/SG, 1983. 768p. il.

BRASIL. Ministério do Meio Ambiente. Mapa de Cobertura vegetal do Bioma Cerrado. Planaltina: Embrapa Cerrados; Uberlândia: Universidade Federal de Uberlândia; Goiânia: Universidade Federal de Goiás (Eds.). 2006a. 1 mapa, colorido, 118cm x 84cm. Escala 1:4.000.000. Disponível em: <http://mapas.mma. gov.br/geodados/brasil/vegetacao/vegetacao2002/cerrado/mapas_pdf/vegetacao/ mosaico/mosaico_cobvegA0.pdf>. Acesso em: 1º nov. 2009.

BRASIL. Ministério do Meio Ambiente. Programa Nacional de Conservação e Uso Sustentável do Bioma Cerrado: Programa Cerrado Sustentável. Brasília, DF: IBAMA e MMA, 2006b. 56 p. Disponível em: <http://www.mma.gov.br/ estruturas/201/_arquivos/programa_cerrado_sustentvel_201.pdf $>$. Acesso em: 25 maio 2011.

BRASIL. Ministério do Meio Ambiente. Monitoramento do desmatamento nos biomas brasileiros por satélite. Brasília, DF: CSR/IBAMA, MMA e PNUD, 2011. 54 p. Disponível em: <http://www.mma.gov.br/estruturas/sbf_chm_rbbio/_arquivos/ relatoriofinal_cerrado_2008_2009_72.pdf>. Acesso em: 25 maio 2011.

BRASIL. Ministério do Meio Ambiente. Plano de ação para prevenção e controle do desmatamento e das queimadas no Cerrado: Subsídios do MMA para o Grupo Permanente de Trabalho Interministerial do PPCerrado. Brasília, DF: IBAMA e MMA, 2010. 186 p. Disponível em: <http://www.mma.gov.br/estruturas/168/_ publicacao/168_publicacao02052011030550.pdf>. Acesso em: 25 maio 2011.

BRASIL. Ministério do Meio Ambiente. Relatório Técnico de Monitoramento do Desmatamento no Bioma Cerrado, 2002 a 2008: Dados Revisados. Brasília, DF: CSR/IBAMA, MMA e PNUD, 2009. 69 p. Disponível em: <http://siscom. ibama.gov.br/monitorabiomas/cerrado/Relatorio\%20tecnico_Monitoramento\%20 Desmate_Bioma\%20Cerrado_CSR_REV.pdf>. Acesso em: 25 maio 2011.

CONSERVATION INTERNATIONAL. Biodiversity Hotspots. Disponível em: <http://www.biodiversityhotspots.org/Pages/default.aspx>. Acesso em: 29 out. 2010. 
COUTINHO, L. M. O conceito de bioma. Acta Botanica Brasilica, v. 20, n. 1, p. 1-11, 2006.

ESRI ArcGIS for Windows. ArcMap Version 9.3. Licence type ArcInfo. [S.1]: ESRI - Enviromental Systems Research Institute, 2008. 1 CD-ROM.

FAISSOL, S. O Mato Grosso de Goiás. Rio de Janeiro: Serviço Gráfico (SERGRAF) do IBGE, 1952. 140 p., il., mapas. (Biblioteca Geográfica Brasileira, Publicação. n. 9, Série A “Livros").

FELFILI, J. M. Fragmentos de Florestas Estacionais do Brasil Central: diagnóstico e proposta de corredores ecológicos. In: COSTA, R. B. da (Org.). Fragmentação florestal e alternativas de desenvolvimento rural na região Centro-Oeste. Campo Grande, MS: UCDB, 2003.

FELFILI, J. M.; SILVA JÚNIOR, M. C. (Org.). Biogeografia do Bioma Cerrado: Estudo fitofisionômico na Chapada do Espigão Mestre do São Francisco. Brasília: MMA e UnB, 2001. 152p. il.

Instituto Brasileiro de Geografia e Estatística (IBGE). Manual Técnico da Vegetação Brasileira. Série Manuais Técnicos em Geociências, n. 1. Rio de Janeiro, 1992, 92 pgs.

Instituto Brasileiro de Geografia e Estatística (IBGE). Mapa de Biomas do Brasil: primeira aproximação. Rio de Janeiro: IBGE, 2004a. 1 mapa, colorido. Escala 1:5.000.000. Disponível em: <ftp://geoftp.ibge.gov.br/mapas/tematicos/mapas murais/biomas.pdf>. Acesso em: 20 out. 2008.

Instituto Brasileiro de Geografia e Estatística (IBGE). Mapa de Vegetação do Brasil. Rio de Janeiro: IBGE, 2004b. 1 mapa, colorido. Escala 1:5.000.000. Disponível em: <ftp://geoftp.ibge.gov.br/mapas_tematicos/mapas_murais/vegetacao.pdf>. Acesso em: 20 out. 2008.

Instituto Brasileiro de Geografia e Estatística (IBGE). IBGE lança o Mapa de Biomas do Brasil e o Mapa de Vegetação do Brasil, em Comemoração ao Dia Mundial da Biodiversidade. Rio de Janeiro: IBGE, 2004c. Disponível em: <http://www. ibge.gov.br/home/presidencia/noticias/noticia_visualiza.php?id_noticia=169>. Acesso em: 4 set. 2012.

LEAL, O. Viagem às terras goyanas (Brazil Central). Goiânia: Ed. UFG, 1980. 255p. il. (Coleção Documentos Goianos, n. 4).

MACHADO, R. B. et al. Estimativas de perda da área do Cerrado brasileiro. Relatório técnico não publicado. Brasília: Conservação Internacional, 2004. 23p.

MATTOS, R. J. da C. Chorographia histórica da província de Goyaz. Goiânia: Líder, 1979. $185 \mathrm{p}$.

MYERS, N. et al.. Biodiversity hotspots for conservation priorities. Nature, v. 403, p. 853-858, 2000.

OLIVEIRA-FILHO, A. T.; RATTER, J. A. 2002. Vegetation Physiognomies and Woody Flora of the Cerrado Biome. In: OLIVEIRA, P. S.; MARQUIS, R. J. (Eds.). The Cerrados of Brazil: Ecology and Natural History of a Neotropical Savanna. New York: Columbia University Press, 2002. p. 91-120, 398 p. il. 
RIBEIRO, J. F.; WALTER, B. M. T. Fitofisionomias do Bioma Cerrado. In: SANO, S. M.; ALMEIDA, S. P. (Org.). Cerrado: ambiente e flora. Planaltina, DF: EmbrapaCPAC, 1998. p. 89-166.

SAINT-HILAIRE, A. de. Viagem à província de Goiás. Belo Horizonte: Itatiaia; São Paulo: Ed. USP, 1975. 158 p. il. (Coleção Reconquista do Brasil, v. 8).

SANO, E. E. et al. Mapeamento semidetalhado do uso da terra do Bioma Cerrado. Pesquisa Agropecuária Brasileira, v. 43, p. 153-156, 2008.

SISTEMA ESTADUAL DE ESTATÍSTICA E INFORMAÇÕES GEOGRÁFICA DE GOIÁS (SIEG). Secretaria do Planejamento e Desenvolvimento do Estado de Goiás (Seplan). Base cartográfica e mapas temáticos do estado de Goiás: Arquivos SIGs (shape) - base cartográfica, clima e solos. Disponível em: <http://www.sieg.go.gov. br/>. Acesso em: $1^{\circ}$ fev. 2011.

SOCIEDADE BRASILEIRA PARA O PROGRESSO DA CIÊNCIA (SBPC). Ciência explicando ciência - Afinal: o que é e para que serve o Cerrado? Realização: Regional Goiás. Apoio: Ministério da Ciência e Tecnologia (MCT) e Sociedade Brasileira para o Progresso da Ciência (SBPC) Regional Goiás, [2010]. 1 DVD colorido, 15'40”. Produzido por Acesso Produção.

SPIX, J. B. V.; MARTIUS, K. F. P. V. Viagem pelo Brasil: 1817-1820. v. II. 2. ed. rev./anot., il. São Paulo: Melhoramentos, 1976. Instituto Brasileiro de Geografia e Estatística (IBGE). Rio de Janeiro: Imprensa Nacional, 1938. 389 p.

WAIBEL, L. Capítulos de geografia tropical e do Brasil. 2. ed. anot. Rio de Janeiro: Fundação IBGE, SUPREN, 1979. 326 p., il.

Cassio Henrique Giusti Cezare - Graduação em Engenharia Florestal pela Universidade de São Paulo. Especialização em Análise Ambiental e Geoprocessamento pela Universidade Federal de Goiás. Mestrado em Geografia pela Universidade Federal de Goiás.

Nilson Clementino Ferreira - Possui graduação em Engenharia Cartográfica pela Universidade Estadual Paulista Júlio de Mesquita Filho, mestrado em Engenharia de Transportes pela Universidade de São Paulo e doutorado em Ciências Ambientais pela Universidade Federal de Goiás. Atualmente é professor da Escola de Engenharia Civil da Universidade Federal de Goiás. 